\title{
MEIO AMBIENTE CARCERÁRIO, SUSTENTABILIDADE E AS PARCERIAS PÚBLICO-PRIVADAS ${ }^{*}$
}

Fábio Márcio Piló SILVA ${ }^{1}$

Magno Federici GOMES ${ }^{2}$

\begin{abstract}
${ }^{1}$ Mestre em Direito Ambiental e Desenvolvimento Sustentável pela Escola Superior Dom Helder Câmara. Pós Graduado pela Universidade Cândido Mendes - RJ. Advogado Criminalista. Endereço eletrônico: spilo@uol.com.br

${ }^{2}$ Pós-doutor em Direito Público e Educação pela Universidade Nova de Lisboa-Portugal. Pós-doutor em Direito Civil e Processual Civil, Doutor em Direito e Mestre em Direito Processual, pela Universidad de Deusto-Espanha. Mestre em Educação pela PUC Minas. Professor do Mestrado Acadêmico em Direito Ambiental e Sustentabilidade na Escola Superior Dom Helder Câmara. Professor Adjunto da PUC Minas e Professor Titular licenciado da Faculdade de Direito Arnaldo Janssen. Advogado Sócio do Escritório Raffaele \& Federici Advocacia Associada. Integrante dos grupos de pesquisa: Regulação Ambiental da Atividade Econômica Sustentável (REGA)/CNPQ-BRA e CEDIS/FCT-PT. ORCID: <http://orcid.org/0000-0002-4711-5310>. Currículo Lattes: <http://lattes.cnpq.br/1638327245727283>. Endereço eletrônico: federici@pucminas.br
\end{abstract}

Recebido em: 01/07/2016 - Aprovado em: 27/10/2016 - Disponibilizado em: 18/12/2016

\section{RESUMO:}

O presente artigo tem por objetivo apresentar uma opção aos reclames carcerários, mais especificamente questionando se a implementação e administração de presídios na forma de parcerias público-privadas (PPPs) seria uma solução válida às precárias situações social, ambiental e humana suportadas pelos detentos e seus familiares no sistema prisional atual. Atualmente, o Estado de Minas Gerais é o único a implementar tal modalidade de parceria para a construção e administração penitenciária, estando o complexo penitenciário existente sob a forma de PPP situado em Ribeirão das Neves, cidade que dista $30 \mathrm{KM}$ de Belo Horizonte, ainda na região metropolitana da Capital das Minas Gerais. O texto tem como objeto central de estudo a primeira e, até então, única penitenciária implementada sob a forma de PPP, utilizando-se como marco teórico as legislações que regulamentam dita forma de parceria na administração pública, quais sejam, a Lei Federal no 11.079/2004, e a Lei Estadual n ${ }^{\circ} 14.868 / 2003$. Assim a pergunta que se propõe é: diante da não ressocialização e não humanização perpetradas nos estabelecimentos prisionais estatais, as PPPs seriam uma forma legalmente válida de se humanizar as cadeias e ressocializar os seus habitantes, alcançando o desenvolvimento sustentável em sua dimensão social? A pesquisa teórica foi a metodologia escolhida em vista da construção de esquemas conceituais específicos e da utilização de processos discursivos e argumentativos para a demonstração do objetivo proposto. Concluiu-se que algo deve mudar na realidade prisional brasileira e as PPPs, que apresentam infraestrutura nos termos do que preceitua a Lei de Execuções Penais, além de tratamento digno aos presos e familiares, vêm se mostrando capazes de trazer dignidade aos que de forma humilde querem pagar por seus erros.

Palavras-chave: Parcerias Público-Privadas. Sistema prisional. Dignidade da pessoa humana. Meio ambiente artificial. Desenvolvimento sustentável.

\section{PRISON ENVIRONMENT, SUSTAINABILITY AND PUBLIC-PRIVATE PARTNERSHIPS}

\begin{abstract}
:
This article aims to present an option to prison claims, specifically questioning whether the implementation and administration of prisons in the form of public-private partnerships (PPPs) would be a valid solution to the precarious social, environmental and human situations supported by detainees and their families in the current prison system.
\end{abstract}

\footnotetext{
${ }^{*}$ Financiamento e Grupo de Pesquisa (CNPQ)
} 
Currently the state of Minas Gerais-Brazil is the only one to implement this type of partnership for construction and prison administration, with the existing prison complex in the form of PPP located in Ribeirao das Neves, a city that is $30 \mathrm{KM}$ away from Belo Horizonte, in the metropolitan area of the Capital of Minas Gerais. The article's main object of study is the first and so far the only penitentiary established in the form of PPP, using as a theoretical framework the regulatory laws about this form of partnership in public administration, namely the Federal Law $n^{\circ} 11.079 / 2004$, and the State Law $n^{\circ} 14.868 / 2003$. Therefore, the question proposed is: considering the non-re-socialization and nonhumanization perpetrated in state prisons, are the PPPs an alternative legally valid to humanize the prisons and resocialize its detainees, achieving sustainable development in its social dimension? The theoretical research was chosen as the methodology considering the construction of the specific conceptual schemes and the use of discursive and argumentative processes for the demonstration of the proposed objective. It was concluded that something must change in the Brazilian prison reality and the PPPs which have the correct infrastructure according to the Law of Criminal Executions and a dignified treatment to the prisoners and their families have proved that they are capable to bring dignity to those who humbly want to pay for their mistakes.

Keywords: Public-Private Partnerships. Prison system. Dignity of human person. Artificial environment. Sustainable development.

\section{INTRODUÇÃO}

É notório que a realidade do sistema carcerário não está em conformidade com a lei geral que regula o cumprimento das penas, bem como com o texto constitucional.

Pelo contrário, encontra-se completamente sucateado e abandonado por dezenas de anos, como é o caso da esmagadora maioria dos estabelecimentos prisionais de Minas Gerais, se dando tal fato, segundo o próprio Estado, pela falta de recursos necessários à melhora da infraestrutura existente, para a contratação de pessoal e para construção de novas unidades.

Assim, o estudo do tema, valendo-se da metodologia teórico-documental, se mostra relevante para demostrar ao leitor a realidade do sistema prisional e para informa-lo acerca das proposições aos reclames daqueles que defendem melhores condições aos que no cárcere habitam. Melhorias que não deveriam ser de interesse apenas dos presos, eis que consequências graves de ordem social, ambiental e humana são produzidas no ambiente carcerário pelo ato desidioso do Estado, fazendo com que a Lei de Execuções Penais (LEP) seja descumprida e, consequentemente, uma das funções do cárcere, aqui relatada pela função preventiva especial, qual seja a ressocialização do delinquente, se torne inviável, ao menos na prática. Como consequência, o desenvolvimento em sua dimensão social não se efetiva.

O primeiro capítulo traz aspectos atinentes ao meio ambiente carcerário mineiro, todos relacionados direta ou indiretamente às más condições dos estabelecimentos prisionais. No capítulo seguinte, conceitua-se as parcerias público privadas, legitimadas pela Lei Federal $\mathrm{n}^{\circ}$ 11.079/2004, trazendo maiores detalhes sobre a modalidade de contrato, para, ao final, apresentar o primeiro estabelecimento prisional do país construído sob a forma de contrato firmado entre o ente público concedente e empresa privada. 


\section{ASPECTOS SOCIAIS E AMBIENTAIS DOS PRESÍDIOS MINEIROS}

A realidade prisional brasileira, aqui representada pelos presídios do Estado de Minas Gerais, em nada se assemelha àquele prevista na lei federal que regulamenta a execução das penas no território nacional.

O paradigma para a execução das penas no Brasil, qual seja, a LEP, Lei $\mathrm{n}^{\circ}$ 7.210/1984, já em seu primeiro artigo informa que a execução criminal visa a proporcionar condições para a harmônica integração social do condenado e do internado, vindo a ressaltar uma gama de assistências que o Estado deveria prestar ao preso, tais como a assistência à saúde, material, jurídica, educacional, social e religiosa entre outras. Ocorre que não é isso que se tem visto nos presídios brasileiros.

Através da vivência do escritor, Advogado que milita na espera criminal há 8 (oito) anos, os aspectos sociais, humanos e ambientais são tidos como os piores possíveis, sejam socialmente, ambientalmente ou humanamente tratando.

Em relação ao aspecto social, levando-se em conta o trato do Estado para com os familiares dos detentos, não há qualquer sorte de assistência, esta representada na utopia de se existir uma estrutura mínima de conforto e higiene aos familiares, os quais, na maioria das vezes esperam em filas ao tempo, sob chuva, sol, temperaturas escaldantes, gerando, assim, revolta tanto nos familiares quando nos próprios presos.

Outro ponto que merece ser ressaltado refere-se à análise da atual situação carcerária em relação ao aspecto ambiental visualizado nos presídios, nos quais não há qualquer observância de normas básicas de higiene, de tratamento de esgoto, de poluição do solo, sendo que, em muitos presídios, pocilgas são mantidas em desconformidade com as normas ambientais, bem como observa-se a completa degradação do meio ambiente carcerário.

Tocante aos aspectos humanos violados dentro dos presídios, o meio ambiente carcerário é o fator que mais colabora à degradação do preso, seja no âmbito da sua saúde, seja no psicológico.

Sobre o meio ambiente carcerário, ele é representado pelas condições de vida dentro do ambiente carcerário, tais como a salubridade do local, as condições estruturais necessárias à sobrevivência, ausência de saneamento básico, lotação das celas, higiene e conforto das camas.

\section{A BUSCA PELA DIGNIDADE} SOCIOAMBIENTAL SURRUPIADA NO CÁRCERE

$\mathrm{O}$ art. $3^{\circ}$ da Lei de Execuções Penais, Lei Federal n ${ }^{\circ} 7.210 / 1984$, informa acerca da manutenção dos direitos constitucionais não 
suspensos por sentença aos quais o preso faz jus: “ao condenado e ao internado serão assegurados todos os direitos não atingidos pela sentença ou pela lei” (BRASIL, 1984).

Em regra, quando de uma sentença penal condenatória, são atingidos os direitos à liberdade bem como os direitos políticos, os quais são suspensos. Assim, qualquer outro direito constitucionalmente previsto, ao menos em tese, não deve sofrer qualquer sorte de restrição por parte do Estado.

Infelizmente não é bem o que se vê nas penitenciárias atuais, as quais, diga-se de passagem, se assemelham em muito, às masmorras medievais, eis que o direito a dignidade humana, a saúde, ao laser, ao trabalho e a moradia digna são todos abruptamente surrupiados daquele que se encontra nas mãos do Estado sob o status de reeducando social.

Neste passo, os arts. 10 e 11 da LEP informam acerca da assistência a ser prestada pelo Estado e suas formas:

Art. 10. A assistência ao preso e ao internado é dever do Estado, objetivando prevenir o crime e orientar o retorno à convivência em sociedade. Parágrafo único. $\mathrm{A}$ assistência estende-se ao egresso.

Art. 11. A assistência será: I - material;

II - à saúde;

III - jurídica;

IV - educacional;

V - social;
VI - religiosa (BRASIL, 1984).

$\mathrm{O}$ art. 10 é claro ao afirmar que a assistência ao preso e ao internado é dever do Estado, o qual deve fazê-lo com o objetivo de prevenir o crime e orientar a pessoa para que esta retorne à convivência social. Ocorre que o atual sistema carcerário, nos moldes em que se apresenta, não se mostra nem minimamente capaz de reinserir alguém em uma sociedade, mas tão somente capaz de criar verdadeiros criminosos, cada vez mais revoltados e detentores de conhecimento incompatível com o pacífico convívio em sociedade.

Isso se dá pela incapacidade estatal em administrar todos os estabelecimentos prisionais, bem como pelo descaso político para com certa parcela da sociedade, a qual perde, mesmo que temporariamente, os direitos constitucionais à liberdade e os direitos políticos, não mais podendo votar, enquanto perdurar o cumprimento da pena.

Ocorre que não apenas os que estão reclusos têm a dignidade surrupiada pelo descaso do Estado, mas também os familiares dos detentos, os próprios funcionários que laboram nos estabelecimentos prisionais, os habitantes de seu entorno bem como o meio ambiente, seja ele em seu aspecto prisional, aqui tratado como artificial, bem como em seu aspecto geral, onde o ambiente degradado acaba gerando a contaminação do solo, além de, em muitos casos, preponderar a ausência de saneamento básico, gases são liberados no 
ar pelas pocilgas irregularmente instaladas, e doenças se proliferam.

O desenvolvimento sustentável reclama intervenção imediata a fim de solucionar o impasse que acaba por reproduzir as condutas delituosas, ensejando um ciclo vicioso que prejudica os presos, futuros reincidentes, e as pessoas cumpridoras de seus deveres sociais. Desse modo:

Uma ampla concepção de desenvolvimento requer, obrigatoriamente, que o Estado esteja presente tanto na economia quanto na sociedade, integrado com os demais atores sociais para que seja possível alcançar os objetivos desenvolvimentistas.

Assim, liberdade passa, então, a representar a capacidade crítica e consciente de o indivíduo existir na sociedade em relação à atividade institucional. Mais do que isso, a sustentabilidade requer, além de uma orientação individual e consciente, a firmação de responsabilidades objetivas e públicas, cujo sentido atinja à universalidade, enquanto processo integral de firmação de um contexto seguro e possível para as gerações futuras (ALMEIDA;

ENGELMANN, 2010, p. 24).

Cabe, então, ressaltar que o dispêndio de recursos por parte do Estado com os presos é tido como alto, mas o gasto com os fatores extra muros é ainda maior, principalmente quando não se garante as condições mínimas de higiene, saúde, infraestrutura e auxílio moral e material, tanto aos que se encontra dentro quanto fora do cárcere. A reincidência do preso trás gastos com novos processos e novo cárcere, ou seja, a movimentação reiterada de toda a máquina estatal, sem se esquecer das despesas com o meio ambiente e com a sociedade, que se apresenta como vítima da incapacidade estatal de (re)socializar, uma das primeiras funções da pena, nos termos da teoria preventiva especial, ao lado da punição e da prevenção (temor).

Assim, mudanças se fazem necessárias, e Minas Gerais, através da confecção da Lei Estadual $n^{\circ} 14.868 / 2003$, regulamentou o uso de licitações para contratar mediante PPPs, tendo como objeto o sistema carcerário.

Assim, em 2009 foi licitado o primeiro complexo penitenciário sob a forma aqui tratada, firmada entre o Estado e empresas privadas, que foi inaugurado em 2013 com capacidade para 3.000 (três mil) detentos.

\section{CONCEITO E LEGITIMIDADE DA PARCERIA PÚBLICO-PRIVADA}

Surge a dúvida acerca da origem e do conceito da PPP, algo natural para um instituto relativamente novo, de origem inglesa e que vem sendo difundido no Brasil 
com mais força desde o começo do século

XXI, conforme Ribeiro e Prado (2010).

As PPPs tiveram origem no Direito

inglês, onde conseguiu conquistar grande

sucesso, obtendo grande êxito também em

Países como a "Irlanda, Portugal, Espanha e

África do Sul como sistema de

contraprestação pelo Poder Público ante a

falta de disponibilidade de recursos

financeiros e aproveitamento da eficiência de gestão do setor privado" (DI PIETRO, 2011, p. 143).

No Brasil, a história das PPPs teve termo inicial com o advento da Lei $\mathrm{n}^{0}$ 11.079/2004, que veio para instituir as normas gerais para licitação e contratação de PPP no âmbito da Administração pública, seja ela direta ou indireta.

Segundo narra a mensagem que acompanhou o projeto de lei, "no caso do Brasil, representa uma alternativa indispensável para o crescimento econômico, em face das enormes carências sociais e econômicas do país, a serem supridas mediante a colaboração positiva do setor público e privado" (DI PIETRO, 2011, p. 143-144), e continua informando que:

as Parcerias Públicoprivadas permitem um amplo leque de investimentos, suprindo demandas desde as áreas de segurança pública, saneamento básico até as de infraestrutura viária ou elétrica. Veja-se que o Plano Plurianual do
Governo, encaminhado para vigorar no período de 2004 a 2007, estima a necessidade de investimentos na ordem de $21,7 \%$ do Produto Interno Bruto (PIB) até 2007, como condição à retomada e sustentação do crescimento econômico do país, o que torna indispensável a existência de instrumentos de parcerias que possibilitem a sua concretização (DI PIETRO, 2011, p. 143144).

Acerca do conceito e das características principais da PPP, o art. $2^{\circ}$ da Lei $n^{\circ} 11.079 / 2004$ trás a previsão:

Art. 2o Parceria públicoprivada é o contrato administrativo de concessão, na modalidade patrocinada ou administrativa.

$\S 10 \quad$ Concessão patrocinada é a concessão de serviços públicos ou de obras públicas de que trata a Lei no 8.987 , de 13 de fevereiro de 1995, quando envolver, adicionalmente à tarifa cobrada dos usuários contraprestação pecuniária do parceiro público ao parceiro privado.

$\S 20 \quad$ Concessão administrativa é o contrato de prestação de serviços de que a Administração Pública seja a usuária direta ou indireta, ainda que envolva execução de obra ou fornecimento $\mathrm{e}$ instalação de bens.

§ 3o Não constitui parceria público-privada a concessão comum, assim entendida a concessão de serviços públicos ou de obras públicas de que trata a Lei no 8.987, de 13 de fevereiro de 1995, quando 


\begin{abstract}
não contraprestação pecuniária do parceiro público ao parceiro privado.

$\S 4$ o É vedada a celebração de contrato de parceria público-privada:

I - cujo valor do contrato seja inferior a $\mathrm{R} \$$ 20.000.000,00 (vinte milhões de reais); II - cujo período de prestação do serviço seja inferior a 5 (cinco) anos; ou

III - que tenha como objeto único o fornecimento de mão-deobra, o fornecimento $\mathrm{e}$ instalação de equipamentos ou a execução de obra pública (BRASIL, 2004).
\end{abstract}

Coube ao art. $2^{\circ}$ informar acerca da conceituação das modalidades de parcerias contidas no caput, quais sejam a patrocinada e administrativa ( $\S 1^{\circ}$ e $2^{\circ}$, respectivamente).

Sobre a PPP na modalidade patrocinada, tem-se que a remuneração mescla recursos privados, obtidos por meio da cobrança de tarifas e de recurso público. O termo concessão patrocinada é utilizado pois o Poder Público arca, necessariamente, com uma parte do serviço, sendo o restante remunerado através de tarifas.

Já em relação à PPP na modalidade administrativa, o próprio Poder Público é o usuário do serviço realizado, o que pode acontecer de forma direta ou indireta. A título de exemplo, há o caso da construção e manutenção de um prédio público, em PPP, para abrigar uma repartição pública.
Como requisito pecuniário da PPP, está previsto no inciso I do $\S 4^{\circ}$ do art. $2^{\circ} \mathrm{o}$ valor mínimo de $\mathrm{R} \$ 20.000 .000,00$ (vinte milhões de reais) para o contrato, e como requisito temporal mínimo para a vigência da PPP não menos do que 05 (cinco) anos, conforme preceituado no inciso seguinte do mesmo parágrafo.

Segundo Di Pietro (2011, p. 307330), a concessão de serviço público na forma de parceria entre o ente público e empresas privadas é vista como uma privatização, eis que o Estado enxuga a máquina pública transferindo as atribuições estatais ao setor privado, mesmo que tal entrega ocorra através de contrato administrativo, os quais são regidos pelo direito público, e mantenha a capacidade plena de dispor sobre o serviço bem como o fiscalize.

A autora (2011, p. 307-330) acrescenta que a disponibilidade do serviço público ao setor privado ocorre de forma que este atuará nos parâmetros das empresas privadas, ou seja, dispensáveis de contratar mediante certame público, licitações, além de não estarem sujeitas à fiscalização do Tribunal de Contas.

Em relação a competência para legislar sobre o tema, o art. 24 da Constituição da República de 1988 (CR/1988) prevê as regras no sentido de ser concorrente entre a União, Estados e Distrito Federal a legitimidade legiferante, estabelecendo quais as matérias deverão ser regulamentadas de 
forma geral por aquela e específica por estes.

Dentre as matérias, estabelece o inciso I do art. 24 da CR/1988, está a competência concorrente para legislar sobre direito penitenciário.

Assim, no âmbito do Estado de Minas Gerais, a Lei Estadual no $14.868 / 2003$ informa acerca da modalidade de PPP ora tratada, sendo que o parágrafo único do art. $1^{\circ}$ esclarece acerca da conceituação prática das PPPs, in litteris:

\begin{abstract}
Parágrafo único. As parcerias público-privadas de que trata esta Lei constituem contratos de colaboração entre o Estado e o particular por meio dos quais, nos termos estabelecidos em cada caso, o ente privado participa da implantação e do desenvolvimento de obra, serviço ou empreendimento público, bem como da exploração e da gestão das atividades deles decorrentes, cabendo-lhe contribuir com recursos financeiros, materiais e humanos e sendo remunerado segundo o seu desempenho na execução das atividades contratadas (MINAS GERAIS, 2003).
\end{abstract}

$\mathrm{O}$ inciso IV do $\S^{\circ}$ do art. $5^{\circ}$ da mesma Lei Estadual no 14.868/2003 explicita sobre a autorização para contratos de PPPs na área do sistema penitenciário. Leia-se:

Art. $5^{\circ}$ Podem ser objeto de parceria públicoprivada:

[...]
$\S 1^{\circ}$ As atividades descritas nos incisos do caput deste artigo poderão ser desenvolvidas nas seguintes áreas:

[...]

IV - segurança, sistema penitenciário, defesa e justiça; (MINAS GERAIS, 2003).

Para que a PPP seja viável para o Estado, requisitos são necessários, os quais se encontram previstos no art. 10 da Lei Estadual $\mathrm{n}^{\circ} 14.868 / 2003$ em comento:

Art. 10. Os projetos de parceria público-privada encaminhados ao CGP, sem prejuízo dos requisitos estabelecidos em regulamento, deverão conter estudo técnico que demonstre, em relação ao serviço, obra ou empreendimento a ser contratado:

I - a vantagem econômica e operacional da proposta para o Estado e a melhoria da eficiência no emprego dos recursos públicos, relativamente a outras possibilidades de execução direta ou indireta;

II - a viabilidade dos indicadores de resultado a serem adotados, em função da sua capacidade de aferir, de modo permanente e objetivo, o desempenho do ente privado em termos qualitativos $\mathrm{e}$ quantitativos, bem como de parâmetros que vinculem o montante da remuneração aos resultados atingidos;

III - a viabilidade de obtenção pelo ente privado, na exploração do serviço, de ganhos econômicos suficientes para cobrir seus custos; 
IV - a forma e os prazos de amortização do capital investido pelo contratado; $\mathrm{V}$ - a necessidade, a importância e o valor do serviço em relação ao objeto a ser executado (MINAS GERAIS, 2003).

Observa-se que a PPP vem para trazer vantagens tanto ao Estado, ao agente privado bem como ao beneficiário, sejam elas econômicas, na medida em que reduzam os gastos estatais e tragam lucro àquele que explora a atividade em forma de PPP, ou relacionadas a eficiência do serviço prestado, aferindo-se, de modo permanente e objetivo, o desempenho do ente privado em termos qualitativos e quantitativos.

\section{O CASO DE SUCESSO DA PARCERIA PÚBLICO-PRIVADA EM MINAS GERAIS}

Presídios sob o modelo de concessão em PPPs já se apresentam como realidade no Estado de Minas Gerais, ainda que em um universo muito pequeno, levando-se em consideração o montante total de presídios do Estado.

O primeiro deles foi o complexo penitenciário situado em Ribeirão das Neves, cidade que dista $30 \mathrm{KM}$ de Belo Horizonte, ainda na região metropolitana da capital das Minas Gerais, o qual conta atualmente com 3 (três) unidades prontas de um total de 5 (cinco) a serem implementadas, sendo que cada uma delas ao final comportará 600 (seiscentos) reeducandos.

Para prever sobre a possibilidade de se haver a concessão do serviço penitenciário para empresas privadas em forma de parceria com o ente público, a Lei $\mathrm{n}^{\circ} 14.868 / 2003$ de Minas Gerais explicita em seu $\S 1^{\circ}$, art. $5^{\circ}$, a autorização para contratos de PPPs na área do sistema penitenciário.

O objetivo habitacional do complexo penitenciário é abrigar presos tanto do regime fechado quanto do semiaberto, os últimos trabalhando externamente e pernoitando no cárcere.

Sobre a parceria aqui tratada, segundo dados colhidos no site "www.ppp.mg.gov.br", o contrato de concessão administrativa para a construção e gestão de complexo penal foi assinado em 16 de junho de 2009, pela Secretaria de Estado de Defesa Social - SEDS e a Concessionária Gestores Prisionais Associados S/A - GPA, trazendo prazo contratual de dois anos para a construção do empreendimento e a gestão prisional por parte da concessionária por um período de 25 anos após o começo das atividades fim, podendo ser prorrogável até o limite de 35 anos. Também está previsto no contrato firmado um teto remuneratório por preso no valor de $\mathrm{R} \$ 2.100,00$ (dois mil e cem reais) por mês, valor, segundo informado no mesmo site, $20 \%$ abaixo do atual valor suportado nas penitenciárias mantidas pelo Estado (MINAS GERAIS, 2014, internet). 
A realidade do novo complexo habitacional é aqui apresentada por informações colhidas pelos próprios autores, que, acerca da estrutura local, observaram que a prioridade foi o respeito à CR/1988 e à LEP, porque para todos os presos são fornecidos entretenimento, educação, alimentação digna, médicos, dentistas e psicólogos; aos familiares que frequentam o presídio, há um local amplo, arejado e coberto, o qual dispõe de mesas para convivência, banheiros e bebedouros, possibilitando que os familiares aguardem para a entrega de pertences e visitação com o mínimo de dignidade, além do respeito ao meio ambiente, pois se trata de um local que observa os ditames de sustentabilidade ambiental, sempre limpo e organizado, tudo isso não passando de uma obrigação contratual do parceiro para com o Estado, o qual vincula o cumprimento de objetivos ao pagamento da remuneração prevista.

Sobre os aspectos obrigacionais que envolvem a PPP para a construção e administração dos presídios, nos seguintes termos explana Losekann (coordenador do Departamento de Monitoramento e Fiscalização do Sistema Carcerário e do Sistema de Execução de Medidas Socioeducativas do Conselho Nacional de Justiça), na reportagem de Bandeira (2013):

Se esse modelo de parceria público-privada de gestão penitenciária possibilitar a qualificação e a ressocialização dos presos, como prevê o contrato de concessão administrativa, eu aposto nessa ideia. Hoje, pelo modelo público atual, o preso sai pósgraduado em criminalidade", afirmou o coordenador do Departamento de Monitoramento e Fiscalização do Sistema Carcerário e do Sistema de Execução de Medidas Socioeducativas do Conselho Nacional de Justiça (DMF/CNJ), Luciano Losekann, sobre as atividades do Complexo Penitenciário PúblicoPrivado de Ribeirão das Neves, inaugurado este mês, na região metropolitana de Belo Horizonte, em entrevista concedida à TV Justiça.

Construído e administrado pela iniciativa privada, por um consórcio de empresas (Gestores Prisionais Associados) em parceria com o estado de Minas Gerais, o modelo, pioneiro no Brasil, obriga todos os presos a uma rotina diária de estudo (quatro horas) e trabalho (seis horas) e prevê multas aos parceiros privados caso as obrigações previstas não estejam de acordo com os padrões definidos no contrato. "Esse sistema é semelhante ao sistema existente na Inglaterra. A empresa não recebe todo o repasse de recurso se não cumprir determinados padrões. Diferentemente do sistema de cogestão, em que geralmente uma empresa é a vencedora da licitação, aqui é um consórcio de empresas que exploram determinados serviços delegados durante determinado tempo. Então, se os serviços de educação 


\begin{abstract}
não estão no padrão exigido pelo poder concedente (aqui, o governo de Minas Gerais), a empresa deixa de receber ou recebe uma quantia menor dos recursos", explica Losekann.

As empresas participantes do consórcio têm como responsabilidade os serviços de atenção médica; de educação básica e cursos profissionalizantes, além de alimentação e assistência jurídica e psicológica. Ao poder público caberá a fiscalização dessas atividades, além da segurança armada nas muralhas e a segurança externa em cada unidade que compõe o Complexo Penal. A nova unidade contará com recursos tecnológicos de ponta para evitar o contato dos agentes com os presos e permitir melhor controle nas ações dos detentos. Uma empresa terceirizada de auditoria fará inspeções periódicas a fim de verificar se as exigências previstas em contrato estão sendo cumpridas. Até o final deste ano, a previsão é de que três mil detentos sejam alocados nas cinco unidades do Complexo (BANDEIRA, 2013, internet).
\end{abstract}

No caso de Minas Gerais, conforme informado por Losekann em entrevista à TV Justiça, o parceiro tem o recebimento do valor mensal devido pelos serviços prestados ao Poder Público condicionado ao cumprimento das obrigações de excelência previamente estipuladas em contrato, chamados de indicadores de desempenho, fazendo com que o parceiro trabalhe para manter o nível de excelência pactuado com o Estado. Dessa forma quem sai ganhando são os reeducandos, os familiares, o meio ambiente e toda a sociedade em geral, a qual possui maiores chances de ver aquele preso completamente recuperado e apto a voltar ao convívio social (BANDEIRA, 2013, internet).

O site criado pelo governo de Minas Gerais para informar acerca das parcerias público-privadas (“www.ppp.mg.gov.br”) esclarece quais são os principais indicadores a serem observados pelo executor dos serviços:

O número de fugas; O
número de rebeliões e/ou
motins; Or nível
educacional dos internos;
A proporção dos internos
que trabalham; A
quantidade e qualidade dos
serviços de saúde
prestados; A quantidade e
qualidade da assistência
jurídica e psicológica aos
internos (MINAS
GERAIS, 2014).

Assim, condiciona-se o recebimento integral da remuneração devida ao cumprimento dos indicadores de desempenho, o que faz com que, em correndo tudo conforme planejado pelo parceiro privado, as condições carcerárias se aproximem ao máximo daquelas previstas tanto na CR/1988 quanto na LEP, segundo Muraro (2012).

O paradigma para a execução das penas no Brasil, qual seja, a Lei $\mathrm{n}^{\circ}$ 7.210/1984), já em seu primeiro artigo informa que a execução criminal visa a 
proporcionar condições para a harmônica integração social do condenado e do internado, vindo a ressaltar uma gama de assistências que o Estado deveria prestar ao preso, tais como a assistência a saúde, material, jurídica, educacional, social e religiosa entre outras. Ocorre que não é isso que se tem visto nos presídios brasileiros, mas os presídios mantidos sob a forma de PPPs vieram para mudar a realidade atualmente dominante.

Apesar dos aspectos positivos acima elencados, indaga-se o porquê de o modelo de concessão aqui estudado não ser mais amplamente difundido.

\section{CONSIDERAÇÕES FINAIS}

O presente trabalho buscou analisar a validade e aplicabilidade das PPPs tendo com objeto a construção e gestão de penitenciárias, sendo que, para tanto, brevemente apresentou elementos informadores da degradante situação atual dos estabelecimentos prisionais do Brasil, ante o paradigma exemplificador das penitenciárias de Minas Gerais.

A realidade prisional brasileira apresenta-se de forma precária, desumana e completamente contrária à LEP, além de estar em desconformidade também com a normatização ambiental, seja ela constitucional ou federal. Minas Gerais, em 2009, abriu edital de licitação, tendo como objeto a concessão, em regime de PPP, para construção e gestão de um estabelecimento prisional.

$\mathrm{Na}$ época, as PPPs já se mostravam uma realidade no território pátrio, sendo normatizadas, a nível geral, pela Lei Federal $\mathrm{n}^{\mathrm{o}} 11.079 / 2004$ e, em Minas Gerais, pela Lei Estadual $n^{0} 14.868 / 2003$. Todavia, não eram uma realidade prática tendo como objeto o sistema penitenciário, apesar de haver previsão no inciso IV, do $\S 1^{\circ}$, do art. $5^{\circ}$ da Lei Estadual $n^{0} 14.868 / 2003$, que já trazia menção acerca da possibilidade de se fazer dita modalidade de parceria no âmbito da segurança, sistema penitenciário, defesa e justiça.

Assim, valendo-se da previsão legal insculpida na legislação local, o Estado de Minas Gerais foi o pioneiro no que toca a tentativa de reverter a situação dramática suportada pelos detentos e por todos aqueles que se sujeitam, direta e indiretamente, ao mundo carcerário, ocasião em que concedeu de forma integral a empresa privada o direito de construir e explorar o sistema carcerário em Ribeirão das Neves, vindo, assim, a ser criado o primeiro complexo penitenciário em forma de PPP do Brasil, tendo capacidade para 3.000 (três mil) detentos em regime fechado e semiaberto.

A construção de presídios em forma de parceria entre o ente público e empresas privadas traz também como objetivos contratualmente previstos o respeito aos ditames sociais, ambientais e humanos, 
assegurados tanto nos direitos constitucionais fundamentais, quanto na lei que regulamenta a execução das penas no Brasil, qual seja, a LEP (Lei n $\left.{ }^{0} 7.210 / 1984\right)$, sob pena de, em não havendo o cumprimento dos objetivos contratuais, ficar o parceiro privado sem o recebimento dos valores mensalmente contratados a título de remuneração, o que faz com que o nível de excelência da execução dos serviços seja alto.

Esse paradigma pode ser efetivado em todos os âmbitos da Federação, além de concedidos por entidades da Administração Pública direta e indireta, nos termos do art. $1^{\circ}$ da Lei Federal $\mathrm{n}^{\mathrm{o}} 11.079 / 2004$, sempre mediante lei autorizadora e contraprestação pecuniária do parceiro público ao parceiro privado.

Assim, a melhoria da situação carcerária no Brasil está na realização de mais PPPs, nos moldes como a celebrada em Minas Gerais, pois, além de enxugar a máquina pública, a sociedade ganha, pois há o aumento no grau de ressocialização, reinserção do detento no ambiente social comum e diminuição da reincidência que, por sua vez, produz o aumento da criminalidade. Além da sociedade, os próprios condenados e seus familiares, que passam a ser tratados de forma digna, humana e em respeito às leis nacionais. Ademais, o meio ambiente natural também é beneficiado, posto que se adota métodos válidos de tratamento de esgoto e emissão de gases nas PPPs. Com isso, alcança-se um ciclo virtuoso, o que é pretendido pelo princípio constitucional estruturante do desenvolvimento sustentável.

\section{REFERÊNCIAS}

ALMEIDA, Ana Paula de; ENGELMANN, João Gilberto. Direito e sustentabilidade: perspectivas de uma geração livre e possível. Revista Veredas do Direito, Belo Horizonte, ž v. 7, n. 13/14, p. 11-25, jan./dez. 2010.

Disponível em: <http://www.domhelder.edu.br/revista/index. php/veredas/article/viewFile/177/140>. Acesso em: 24 dez. 2015.

BANDEIRA, Regina. Só ressocialização viabiliza parceria público-privada em presídios, diz juiz. Agência CNJ de notícias, CNJ, 2013. Disponível em: <http://www.cnj.jus.br/noticias/cnj/23285juiz-diz-apoiar-parceira-publico-privada-nagestao-de-presidios-se-houverressocializacao-de-presos >. Acesso em: 21 mar. 2015.

BRASIL. Constituição da República Federativa do Brasil de 1988. Diário Oficial da União, Brasília, 05 out. 1988.

BRASIL. Lei $\mathrm{n}^{\mathrm{o}}$ 7.210, de 11 jul. 1984. Institui a Lei de Execução Penal. Diário Oficial, Brasília, 13 jul. 1984. Disponível em: <http://www.planalto.gov.br/ccivil_03/leis/17 210.htm>. Acesso em: 22 mar. 2015.

BRASIL. Lei $\mathrm{n}^{\mathrm{o}}$ 11.079, de 30 dez. 2004. Institui normas gerais para licitação e contratação de parceria público-privada no âmbito da administração pública. Diário Oficial, Brasília, 31 dez. 2004. Disponível em:

<http://www.planalto.gov.br/ccivil_03/_ato20 04-2006/2004/lei/111079.htm>. Acesso em: 22 mar. 2015. 
DI PIETRO, Maria Sylvia Zanella. Parcerias

na administração pública: concessão, permissão, franquia, terceirização, parceria público-privada e outras formas. 8. ed. São

Paulo: Atlas, 2011.

MINAS GERAIS. Lei Estadual n ${ }^{\circ} 14.868$, de 16 dez. 2003. Dispõe sobre o Programa Estadual de Parcerias Público-Privadas.

Diário Oficial, 16 dez. 2003. Disponível em: <http://www.ipsm.mg.gov.br/arquivos/legisla coes/legislacao/leis/lei_14868.pdf $>$. Acesso em: 22 mar. 2015.

MINAS GERAIS. Programa de Parceria Público-Privada do Estado de Minas Gerais. Projeto PPP no Sistema Penal: cerca de 3000 vagas prisionais. PPP MG, 24 jan. 2014. Disponível em:

<http://www.ppp.mg.gov.br/ajuda/page/248projeto-ppp-no-sistema-penal-cerca-de-3000vagas-prisionais>. Acesso em: 22 mar. 2015.

MURARO, Celia Cristina. As parcerias público-privadas no sistema penitenciário brasileiro. Âmbito Jurídico, Rio Grande, v. 15, nº 103, ago. 2012. Disponível em: $<$ http://www.ambitojuridico.com.br/site/index.php/?n_link=revista _artigos_leitura\&artigo_id=12136\&revista_ca derno=4> . Acesso em: 19 mar. 2015.

RIBEIRO, Maurício Portugal; PRADO, Lucas Navarro. Comentários à lei de PPP Parceria público-privada: fundamentos econômico-jurídicos. São Paulo: Malheiros, 2010 . 